3 Taylor MJ. Timing of onset of lithium relapse prevention in bipolar disorder: evidence from randomised trials. Br J Psychiatry 2018; 213: 664-6.

Matthew Taylor, Consultant Psychiatrist, University Department of Psychiatry, Warneford Hospital, Oxford. Email: matthew.taylor@psych.ox.ac.uk

doi:10.1192/bjp.2019.66

\section{Montgomery and changes to the process of consent: debate required}

The doctrine of precedence is a feature of common law jurisdictions such as that in England and Wales, Scotland and other areas of the UK. It allows for judgments made in courts of law to be followed by other courts, unless they are replaced by different decisions in a higher court. In a similar fashion, rulings in courts tend to be taken by professions and incorporated into practice. The case discussed by Adshead et al refers to a judgment in the UK's highest court, where a decision about information required to achieve appropriate consent for the delivery of a pregnancy was heard. ${ }^{1}$ Adshead et al argue that the judgment should be followed when, for example, medication is discussed with patients by psychiatrists.

In order for a lower court to follow a previous judgment, the subsequent case must be similar in nature or fact, so that precedence can be applied. Therefore, it follows that if a court judgment is to be applied to clinical practice, then the case it concerns should be similar to the patient being seen. As a child and adolescent psychiatrist, I am interested in the application of the judgment to patients under 18, and whether Montgomery is similar enough to be applied to the process of consenting minors to take psychotropic medication? The legal case concerned a 'clearly highly intelligent' mother with diabetes. ${ }^{2}$ Is this the case for a significant number of patients seen in child and adolescent mental health services? Does the procedure of a caesarean section or an instrumental delivery of a baby resemble closely enough aspects of treatment using psychotropic medication?

Clearly, informed consent needs to involve the presentation of appropriate information to enable patients to make a choice, and that information presented needs to be adequate and tailored to the individual concerned. Making a patient aware of material risks of treatment or procedures is a laudable aim, but knowing every patient's life, aspirations and interests in sufficient detail in which to form a definitive view of what risks to include may be unachievable in normal clinical practice. I fear that, in order to avoid criticism and censure, clinicians may take an approach that presents all risk information without filter or context. Some might describe this as defensive medicine.

I make these points, not to imply they represent my opinion or point of view, but rather to stimulate debate and argument, so that we, as a profession, are not necessarily bound by decisions that are made in situations that cannot be properly applied to the patient in front of us. Accusations of pedantry and missing the point could be levelled at such arguments, but the law is precise, and so should those who follow the law. This is such a very important topic that could have ramifications throughout the psychiatric (and medical) world. I note that Adshead et al recommend the Royal College of Psychiatrists' Professional Practice and Ethics Committee update Good Psychiatric Practice to incorporate the Montgomery ruling. I say that we, as a membership and profession, need to have a debate first, before agreeing what becomes our College's guidance for consent, as this will be the guidance to which our practice is measured against.

\section{Declaration of interest}

I was a member of the Professional Practice and Ethics Committee from 2012 to 2016.

\section{References}

1 Adshead G, Crepaz-Keay D, Deshpande M, Fulford KWM, Richards V. Montgomery and shared decision-making: implications for good psychiatric practice. Br J Psychiatry 2018; 213: 630-2.

2 Montgomery v Lanarkshire Health Board [2015] UKSC 11.

John Watts, Child and Adolescent Psychiatrist, South London and Maudsley NHS Foundation Trust, UK. Email: john.watts@nhs.net

doi:10.1192/bjp.2019.67

\section{Author's reply}

We are grateful to Dr Watt for his thoughtful response. He makes the very point that we raised in our editorial; namely that applying Montgomery in practice raises interesting questions for different psychiatrists working in different settings. One of us is a consultant in forensic child and adolescent mental health services so recognises the issues Dr Watts describes; another is a consultant in long-term secure care where patients and professionals may have different value perspectives on risk.

We therefore entirely concur that more debate and discussion about the Montgomery judgment is needed; and we hoped our editorial would stimulate this kind of debate. We especially hope that the Montgomery judgment will encourage psychiatrists in all settings to think about how best to establish dialogue with patients about treatment that allows exploration of different values from the both the patients' and the professionals' perspective. It is this emphasis on exploration of what is important to all parties in terms of treatment experience and outcome (not just risk) that makes Montgomery such an interesting case for psychiatrists.

Gwen Adshead, Consultant Forensic Psychotherapist, Southern Health Foundation Trust, UK; Mayura Deshpande, Consultant Forensic Psychiatrist, Southern Health Foundation Trust, UK; K. W. M. (Bill) Fulford, Emeritus Professor, University of Warwick, UK. Email: g.adshead@nhs.net

doi:10.1192/bjp.2019.68 